\title{
Load Frequency Control Optimization Using PSO (A case of the Power System in Zambia)
}

\author{
Mr. Gabriel Musonda ${ }^{1}$, Prof. Webby Mwaku ${ }^{2}$, Mr. George Mugala ${ }^{3}$, \\ Department of Electrical Engineering, \\ School of Engineering, \\ Copperbelt University, \\ Zambia
}

\begin{abstract}
The objective in this paper is to propose improvement in power system stability and economy of power generation through optimization of Load Frequency Control (LFC) in a four (4) area interconnected power system involving hydro and thermal plants using a particle swarm optimization (PSO) algorithm. Area-1,2 and 3 comprise hydro plants and area-4 comprise thermal plant. This is representative of ninety percent the national electricity power system in Zambia is configured. The system is non-linear because it interconnects hydro and thermal plants. The experiments in MATLAB/SIMULINK seek to determine implementation of LFC optimization and compare results with existing isolated area AGC system used in primary frequency management. PSO-PID controller is used to determine frequency deviation step response of the power system and comparing results produced from isolated AGC system.
\end{abstract}

Keywords: Isolated Area Automatic Generator Control (AGC), Particle Swarm Optimization (PSO), PSO - PID controller, Frequency Deviation Step Response.

\section{INTRODUCTION}

The installed capacity on the Zambian Electricity Power System by the National Power Company (ZESCO) and Independent Power Producers (IPPs) stands at 3187 MW. By 2018, the Electricity Supply Industry (ESI) generation capacity has continued to be largely driven from hydro power, which accounts for 74.94 percent $(2,388.3 \mathrm{MW})$ of the total national installed capacity. Power generation from coal is second at 20.7 percent ( $660 \mathrm{MW})$, followed by diesel at 2.78 percent $(88.6 \mathrm{MW})$, while Heavy Fuel Oil (HFO) accounts for 1.56 percent $(50 \mathrm{MW})$ and solar photovoltaic $(\mathrm{PV})$, less than 0.1 percent $(0.06 \mathrm{MW})$ [1]

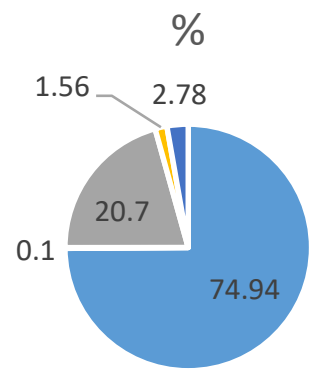

- Hydro - Solar $\square$ Thermal $\square$ HFO - Diesel
The profile of the power system represents huge investment in hydro and least investment in solar photovoltaic systems. As a developing country Zambia should encourage both public and private sector investment in the energy sector to grow its economy. At $3187 \mathrm{MW}$ installed capacity, the economy of Zambia is not expected to grow at no more than $5 \%$ per annum.

Investment in power generation in the last two years alone as seen the sector grow from $2411 \mathrm{MW}$ in 2015 to $3187 \mathrm{MW}$ in 2018. Growth in energy management systems resulted only in policy consumer demand and consumption reduction strategies. Energy serving bulbs were introduced and consumers were encouraged to utilize alternative forms of energy such as gas and solar PV. The approach is sustainable in reducing pressure on the energy infrastructure and less on stability management.

It is projected that approximately above $1000 \mathrm{MW}$ of power will be added to the national installed capacity through the 800MW Batoka hydro power project, multi-facility economic zone (MFEZ) solar project and commissioning of Kafue lower power project. The energy system will most likely become complex with addition infrastructure for power generation and load, hence the need for investment in both supply and demand side management.

Load Frequency Control is primary component of a power system to ensure continuous power supply to the consumer. Technically, power system frequency management is achieved through Automatic Generation Control (AGC). Frequency control divides the load between generators and controls the tie-line power to pre-determined values to maintain sensibly load and generation balance. Zambia's' ESI has a spinning reserve of $70 \mathrm{MW}$ which is insufficient to meet load demand of 180MW capacity of the largest mining industry and hence implement secondary load Frequency Control. 250MW spinning reserve is assumed in this study.

\section{A. Literature review}

Electricity Supply Industry (ESI) in Zambia comprises generator units with diverse capacities and methods of power generation. The ESI is predominantly hydro; these units have comparatively slow ramping rates than steam units. Ramping rates are used to classify generator units. Therefore, it is very important to assign units with similar response rate in each

Fig. 1.1 Electric Energy Distribution in Zambia 
class, to have the correct ramp rates of the plants in the controller and also within the plants of each class.

Generator unit technical specifications on the Zambian ESI were obtained from the power utility firms and the Energy Regulation Board (ERB). We therefore, have three (3) classes of units based on the technical information obtained from the regulator and utility firms.

Table 1.2: Zambian Electricity Supply Industry (ESI) technical specifications

\begin{tabular}{|l|c|c|c|c|}
\hline POWER PLANT & TYPE & CLASS & $\begin{array}{c}\text { NUMBER OF } \\
\text { UNITS AND UNIT } \\
\text { CAPACITY (MW) }\end{array}$ & $\begin{array}{c}\text { TOTAL } \\
\text { CAPACITY } \\
\text { (MW) }\end{array}$ \\
\hline Kariba north Bank \& Extension & Hydro & 1 & $6 \times 180$ & 1080 \\
\hline Kafue Gorge & Hydro & 1 & $6 \times 165$ & 990 \\
\hline Victoria falls & Hydro & 1 & $10 \times 10.8$ & 108 \\
\hline Itezhi-tezhi & Hydro & 1 & $2 \times 60$ & 120 \\
\hline ZESCO small power stations & Hydro & 1 & - & 120 \\
\hline Mulungushi & Hydro & 1 & $2 \times 10.5$ & 33 \\
\hline Lusemfiva & Hydro & 1 & $4 \times 6$ & 24 \\
\hline Zengamina & Hydro & 1 & - & 0.75 \\
\hline Maamba & Thermal & 2 & $2 \times 165$ & 660 \\
\hline Ndola Energy & $\begin{array}{c}\text { Heavy Fuel } \\
\text { Oil (HFO) }\end{array}$ & 2 & $6 \times 8.5$ & 51 \\
& & & \\
\hline
\end{tabular}

\section{B. Kariba North Power Plant}

The Kariba North Bank power plant is the largest of all hydroelectric power plants in Zambia. It is located in the southern province of Zambia and became operation in 1962 under the ownership of Central Africa Power Corporation (CAPCO) with a capacity of 600MW [2]. Initial capacity of the power plant had four (4) by $150 \mathrm{MW}$ power generating units. The power plant was upgraded to Six (6) generating units of $180 \mathrm{MW}$ making the installed capacity $1080 \mathrm{MW}$ by 2008. The plant accounts for Thirty-eight percent (38\%) of the national installed capacity. The Six Francis turbine and generator groups of $180 \mathrm{MW}$ each were supplied by Sinohydro of china.

\section{Kafue Gorge Power Plant}

The Kafue Gorge power plant is the second largest of all hydroelectric power plants in Zambia. It is located in the southern province of Zambia and became operation in 1973 under the ownership of Zambia Electricity Corporation with a capacity of $600 \mathrm{MW}$ [2]. Initial design of the plant had four (4) by $150 \mathrm{MW}$ power generating units. The plant was upgraded to Six (6) generating units of $150 \mathrm{MW}$ making the power plant installed capacity $900 \mathrm{MW}$ by 1978 . The total installed capacity of the plant was upgraded to 990MW following the installation of $165 \mathrm{MW}$ Francis turbine by Sinohydro in 2008. The plant accounts for Thirty-five percent $(35 \%)$ of the national installed capacity.

\section{Victoria Falls Power Plant}

Victoria Falls power plant is one of the smallest hydroelectric power plant owned by ZESCO with installed capacity of 108MW. It is located in Livingstone, the provincial capital of southern province. Its contribution to the national installed capacity is $4 \%$. The plant is operated by Ten (10) small runoff river generating units of $10.8 \mathrm{MW}$ capacity.

\section{E. Itezhi-Tezhi Power Plant}

Itezhi-Tezhi power plant has installed capacity of 120MW. Itezhi - Tezhi Power Corporation Limited (ITPC) is a joint venture between Tata Africa Holdings (SA) Pty Limited and ZESCO [1]. The plant is operated by Two (2) by $60 \mathrm{MW}$ generating units commissioned in 2016. The plant is modern with frequency control capability.

\section{F. Maamba Thermal Power Plant}

The project area is located at Maamba Township in Sinazongwe district of Southern province which is about $350 \mathrm{~km}$ from Lusaka, Zambia. Maamba Thermal power plant has a planned capacity of $600 \mathrm{MW}$ out of which $300 \mathrm{MW}$ is installed [3]. Power is transported from Maamba via $48 \mathrm{~km}$ $330 \mathrm{KV}$ transmission line to the Muzuma substation.

\section{G. Mulungushi Power Plant}

Mulungushi hydro plant is a $32 \mathrm{MW}$ power station owned by Lusemfwa Hydro Power Corporation and located in the Central Province of Zambia, approximately $60 \mathrm{~km}$ to the south east of Kabwe [4]. The plant is operated on Two (2) by 6MW Francis turbines installed in 1927 and 2 by $10.5 \mathrm{MW}$ Francis turbines installed in 2009. By international standard the plant is in the category of a mini-hydro plant without primary frequency control capability. The plant contributes less than $2 \%$ of the national installed capacity.

\section{H. Lusemfwa Power Plant}

Lusemfwa hydro plant is a $24 \mathrm{MW}$ power station owned by Lusemfwa Hydro Power Corporation and located in the Central Province of Zambia. The plant is operated by 4 by $6 \mathrm{MW}$ Francis turbines. The station is connected to the ZESCO power network.

\section{Technical Control Strategies}

Frequency control is an essential component of the power system. Frequency control is directly related to load and real power generation balance. Load frequency control is compounded by the constraint that there is no practical storage of electric energy in the power system, hence electricity has to be generated according to demand. However, the frequency parameter can be monitored at any point on the grid based on the fact that a power system connected by alternating current (AC) lines and transformers constitutes a synchronous grid where only one frequency subsists.

The first attempt at coordinating power generation in Zambia was taken in the early 1950 s when at least four stations with a combined capacity of $120 \mathrm{MW}$ were connected to a central switching station at Kitwe [2]. Beyond the initiative, there have not been significant investment in frequency control technology in the ESI in Zambia.

The technical specifications on which the power system frequency control should be maintained are defined in the Zambia Bureau Standards, Electricity Supply, power quality and reliability defining nominal frequency as $50 \mathrm{~Hz}$ with maximum deviation for networks as follows [5]; 
- for grid networks: $\pm 2,0 \%$ at all times $(49 \mathrm{~Hz}$ to 51 $\mathrm{Hz}$ )

- for islanded networks: $\pm 5,0 \%$ at all times $(47.5 \mathrm{~Hz}$ to $52.5 \mathrm{~Hz}$ )

In order to institute control of the power system, the profile of power plants need to be appreciated in terms of primary control operational costs dynamics. The following primary control assessment apply to power generation units;

- Hydropower: Negligible fuel costs, minimal efficiency losses and is a Low cost source of electrical energy

- Thermal units: High fuel costs, high efficiency losses and is a High cost source of electrical energy

- Photovoltaics units: Non-dispatchable units, unable to provide spinning reserve and is a very high cost source of electrical energy.

Therefore, for an ESI such as the one in Zambia with low electricity tariffs, frequency control can be implemented on hydro units because of low cost implication, and not feasible on thermal and PV units because of high operating cost. Size of the plant is another determining factor for frequency control. Smaller plants do not possess sufficient spinning reserve to influence significant match in load and generation to stabilize grid frequency. Therefore, frequency control is considered only for hydro units with generation capacity above $50 \mathrm{MW}$.

The Automatic Generation Control (AGC) is installed on the four major power stations. Installed AGC on power stations operates in isolated area mode. This is called primary load frequency control. While primary control facilitates increase or decrease in power generation to match the load, secondary control is required for restoration of frequency to nominal value. Both primary and secondary control are components of load frequency control which is an important aspect of energy efficiency and demand (load) side management

\section{SINGLE AREA LOAD FREQUENCY CONTROL}

To determine the shortfalls of the power system in Zambia, isolated frequency response of areas used for primary frequency management is simulated in MATLAB/SIMULINK. The simulations are used to determine the negative side of lack of secondary control to provide system stability and economy of power generation by electricity supply industry in Zambia. The frequency response deviations are determined from the closed loop transfer functions of individual systems. System parameters in the table below are used for simulations.

Power System parameters used in simulation are standard parameters used for load frequency control experiments presented by in the table below with minor adjustments to match system parameters for the power system in Zambia [6]. Table. 2.1 Power System Parameters

\begin{tabular}{|l|c|}
\hline \multicolumn{1}{|c|}{ Parameters } & values \\
\hline \multicolumn{1}{|c|}{ Kariba North Hydro, Kafue Gorge Hydro \& Itezhi-tezhi } & $4.9 \mathrm{~s}$ \\
\hline Speed governor time constant $\left(T_{G}\right)$ & $28.749 \mathrm{~s}$ \\
\hline Transient droop time constant $\left(T_{R S}\right)$ & $0.2 \mathrm{~s}$ \\
\hline Main servo time constant $\left(T_{G S}\right)$ & $1.1 \mathrm{~s}$ \\
\hline Water time constant $\left(T_{W}\right)$ & $24 \mathrm{~Hz} / \mathrm{pu} \mathrm{MW}$ \\
\hline Speed governor regulation $\left(R_{H}\right)$ & $80 \mathrm{~Hz} / \mathrm{pu} \mathrm{MW}$ \\
\hline Load model gain $\left(K_{P S}\right)$ & $13 \mathrm{~s}$ \\
\hline Load time constant $\left(T_{P S}\right)$ & \\
\hline \multicolumn{1}{|c|}{ Maamba Thermal } & $0.08 \mathrm{~s}$ \\
\hline Speed governor time constant $\left(T_{G}\right)$ & $0.3 \mathrm{~s}$ \\
\hline Turbine time constant $\left(T_{T}\right)$ & $27 \mathrm{~Hz} / \mathrm{pu} \mathrm{MW}$ \\
\hline Speed governor regulation $\left(R_{H}\right)$ & $120 \mathrm{~Hz} / \mathrm{pu} \mathrm{MW}$ \\
\hline Load model gain $\left(K_{P S}\right)$ & $20 \mathrm{~s}$ \\
\hline Load time constant $\left(T_{P S}\right)$ & \\
\hline \multicolumn{1}{|c|}{ Power system } & $0.425 \mathrm{puMW} / \mathrm{Hz}$ \\
\hline Frequency bias constants $\left(B_{1}, B_{2}, B_{3}, B_{4}\right)$ & -1 \\
\hline$a=2 * p i * T 12=2 * p i * T 23=2 * p i * T 34=2 * p i * T 41$ & $50 \mathrm{~Hz}$ \\
\hline Frequency & \\
\hline
\end{tabular}

A. Non-reheat Steam Turbine (Maamba Power Station)

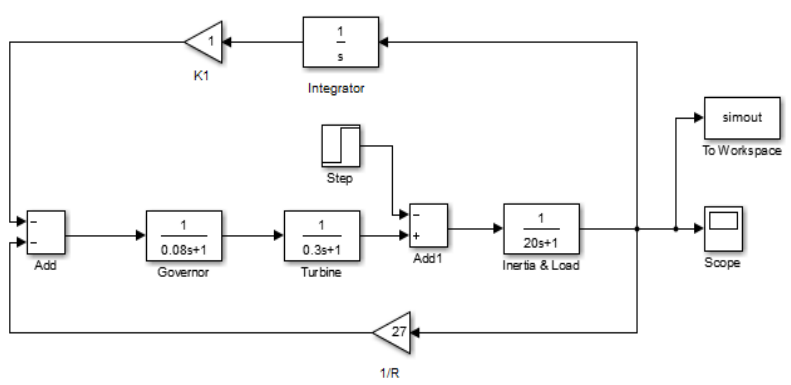

Fig 2.2 Simulink Model of isolated Steam Turbine at Maamba

The turbine rated output is $660 \mathrm{MW}$ at nominal frequency 50 Hz. A sudden load change of $180 \mathrm{MW}$ ( $\Delta P_{L}=0.273$ Per unit) is assumed. $180 \mathrm{MW}$ represents the largest installed single generator unit and largest single mining load.

To determine the single loop load frequency control we have used the transfer function of the control system with only $-\Delta P_{L}$ as input [7].

$$
\frac{\Delta \Omega(s)}{-\Delta P_{L}}=\frac{s\left(1+\tau_{g} s\right)\left(1+\tau_{t} s\right)}{s(2 H s+D)\left(1+\tau_{g} s\right)\left(1+\tau_{t} s\right)+K_{i}+s / R}
$$

Substituting the system parameters, we get the closed loop transfer function as:

$$
\frac{\Delta \Omega(s)}{-\Delta P_{L}}=\frac{0.024 s^{3}+0.38 s^{2}+s}{0.48 s^{4}+7.624 s^{3}+20.38 s^{2}+28 s+1}
$$


Frequency deviation step response is shown below.

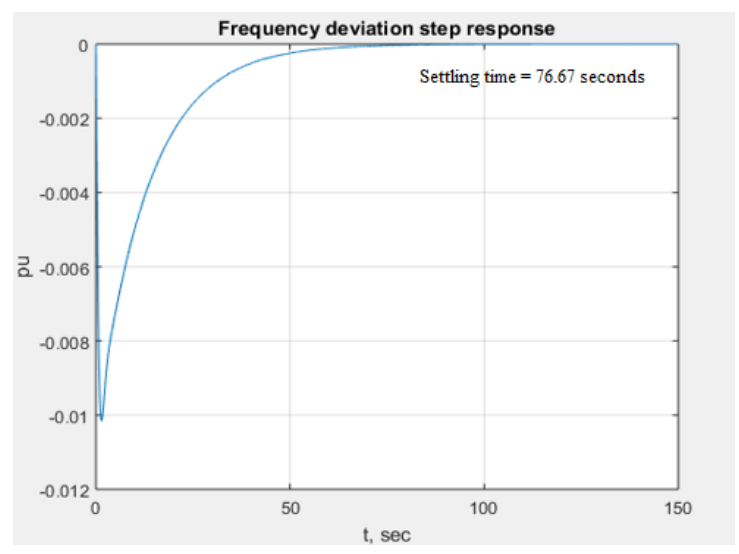

Fig. 2.3 AGC frequency deviation step response for isolated Steam Turbine at Maamba

B. Hydro Turbine (Kafue Gorge)

The turbine rated output is $990 \mathrm{MW}$ at nominal frequency 50 Hz. A sudden load change of $180 \mathrm{MW}$ ( $\Delta P_{L}=0.182 \mathrm{Per}$ unit) occurs.

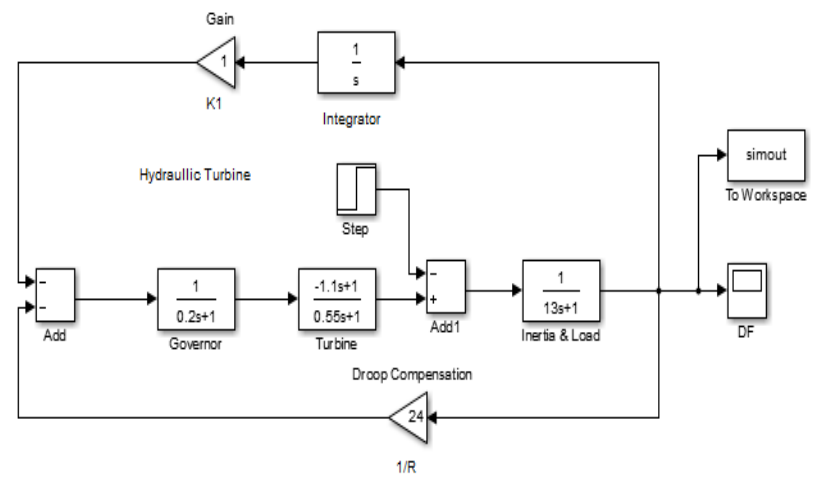

Fig 2.4 Simulink Model of isolated Hydro Turbine at Kafue Gorge

$$
\frac{\Delta \Omega(s)}{-\Delta P_{L}}=\frac{2.695 s^{3}+5.45 s^{2}+s}{35.035 s^{4}+73.545 s^{3}+18.45 s^{2}+25 s+1}
$$

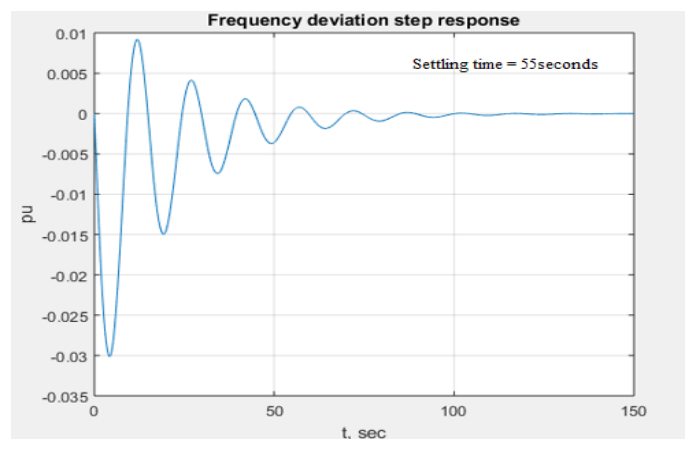

Fig.2.5 AGC Frequency deviation step for isolated hydro power station at Kafue Gorge

\section{Kariba North Hydro Power Plant}

The turbine rated output is $1080 \mathrm{MW}$ at nominal frequency 50 Hz. A sudden load change of $180 \mathrm{MW}$ ( $\Delta P_{L}=0.167$ Per unit) occurs.

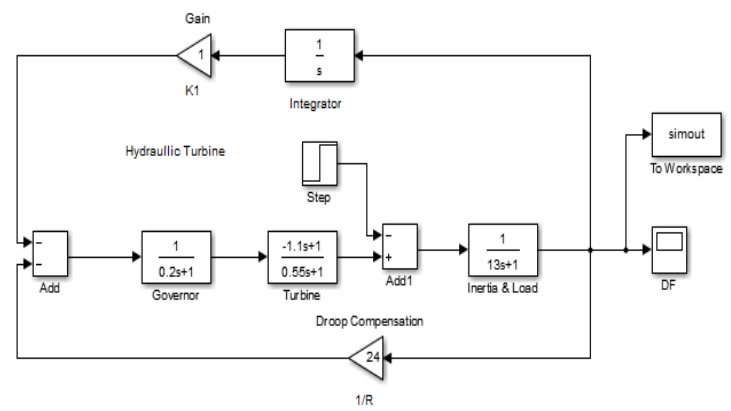

Fig 2.6 Simulink Model of isolated Hydro Turbine at Kariba North Bank

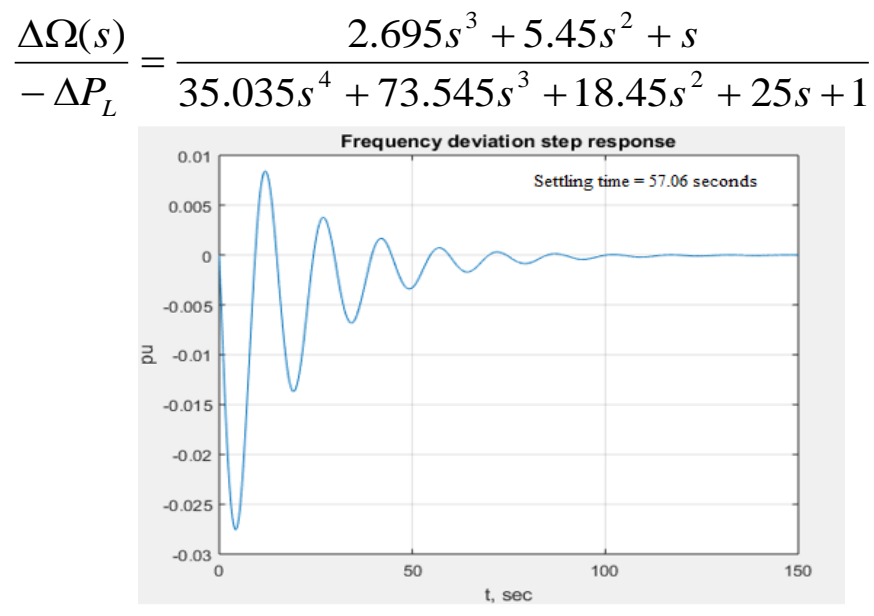

Fig. 2.7 AGC frequency deviation step response for isolated hydro power station at Kariba North

\section{Itezhi-Tezhi North Hydro Power Plant}

The turbine rated output is $990 \mathrm{MW}$ at nominal frequency 50 Hz. A sudden load change of $180 \mathrm{MW}$ ( $\Delta P_{L}=1.5$ Per unit) occurs.

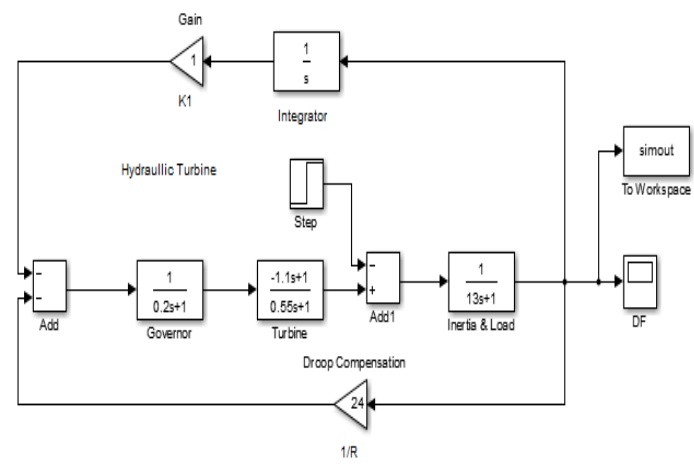

Fig 2.8 Simulink Model of isolated Hydro Turbine at Itezhi-Tezhi

$$
\frac{\Delta \Omega(s)}{-\Delta P_{L}}=\frac{2.695 s^{3}+5.45 s^{2}+s}{35.035 s^{4}+73.545 s^{3}+18.45 s^{2}+25 s+1}
$$




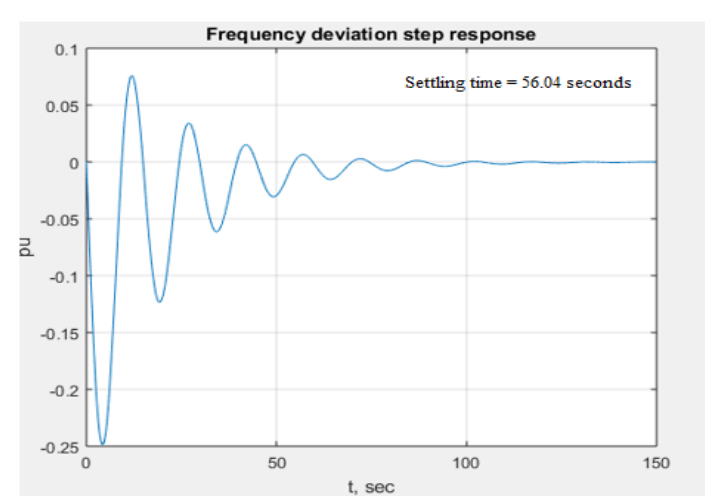

Fig.2.9 Frequency deviation step using AGC for an isolated hydro power station at Itezhi-Tezhi.

\section{LOAD FREQUENCY CONTROL USING PSO}

Particle Swarm Optimization (PSO) is a heuristic optimization technique, developed by Kennedy and Eberhart in 1995, that simulates information sharing between social animals, such as insects and flocks of birds.

The basic idea of the PSO algorithm is that sharing information such as the location of food, creates special group dynamics. PSO simulations are based on massless, volumeless particles that occupy multi-dimensional space moving at a certain velocity and each particle in the search space moves in discrete time steps [8].

PSO simulations are conducted based on the following steps;

i. The fitness of each particle is calculated by a fitness function that takes the current position of a particle as an input.

ii. The change of the particle position is calculated at every iteration by adding the updated velocity vector to the current position.

iii. The change of the particle velocity vector is determined by the previous particle velocity vector, the previous best position, and the groups best position.

Particles that are immediate neighbours of the each other form a group. The memory of each particle best position is called the history best (h-best) position; It is used to model simple nostalgia, a tendency of particles to return to the place that most satisfied them in the past. The group best position (g-best) is the position with the highest fitness that was discovered by the particles of the same group.

Advantages:

i. Few parameters need adjustment for implementation in frequency management optimization.

ii. It does not utilize survival of the fittest criteria; hence entire population is member throughout the process.

iii. PSO unlike GA is not affected by size of the problem.

iv. PSO does not suffer from premature convergence (The major drawback of Genetic Algorithm).
Disadvantages:

i. PSO is constrained by continuous discrete variables. The PID controller has been chosen for this tasks as it has all components required for implementation of automatic frequency control as outlined below;

- The proportional controller will be responsible for maintaining balance between load and generation i.e. reduces the rise time but also results in oscillatory performance.

- The Integral controller will be responsible for restoration of system frequency to nominal value i.e. reduces the steady state error to zero.

- The Derivative controller will be responsible limiting system overshoot as load fluctuates i.e. provides appropriate damping which results in improved transient performance with stability.

The PID controller improves the transient response so as to decrease inaccuracy in amplitude with every oscillation and then output is ultimately settled to a final required value. The block diagram of Proportional Integrative Derivative (PID) controller is shown in Fig.2.1.

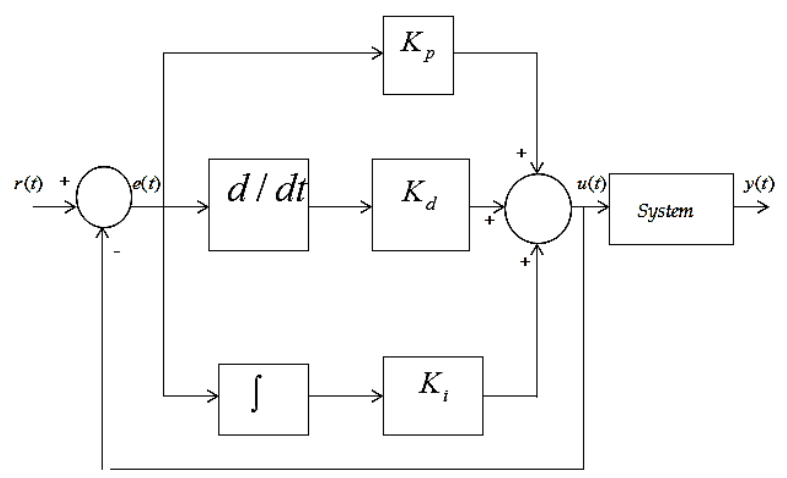

Fig. 3.1 block diagram of a PID controller

The arithmetical equation for the PID controller is given as;

$$
Y(t)=K_{p} e(t)+K_{i} \int_{0}^{t} e(t) d t+K_{d} \frac{d}{d t} e(t)
$$

Where; $y(t)$ is the controller is output and $u(t)$ is the error signal. $K_{p}, K_{i}$ and $K_{d}$ are proportional, integral and derivative gains of the controller [9]. Suitable combination of proportional, integral and derivative actions can provide all the desired performances: fast response, zero steady state error and less offset.

Simulation of the power system was done in MATLAB/SIMULINK and the PSO code was run in MATLAB for tuning of PID controllers. PSO parameters taken for optimizations were:

- $\quad$ Population size $=100$,

- Maximum number of iterations $=120$,

- $\quad \mathrm{c} 1=1.8$

- $\quad \mathrm{c} 2=1.7$ and

- $\quad$ simulation time $=50 \mathrm{~s}$. 
The objective function used in the optimization experiment is the Integral Square Error (ISE). The ISE has the advantage of fast response. ISE is defined by the following expression;

$$
J=I S E=\int \sum_{i=0}^{n}\left(A C E_{i}\right)^{2} d t
$$

And the Area Control Error, ACE is given by;

$$
A C E=\Delta P_{\text {tie }}+B i \Delta f
$$

The Simulink model for LFC and PSO - PID controller was simulated. The optimum gain values obtained by the M-file are transferred to the Simulink model and tested for step load change of 0.063 p.u, corresponding to $180 \mathrm{MW}$ of the $2850 \mathrm{MW}$ load frequency management sector of the power system, applied to area-1.The frequency deviation response are shown in figures respectively.

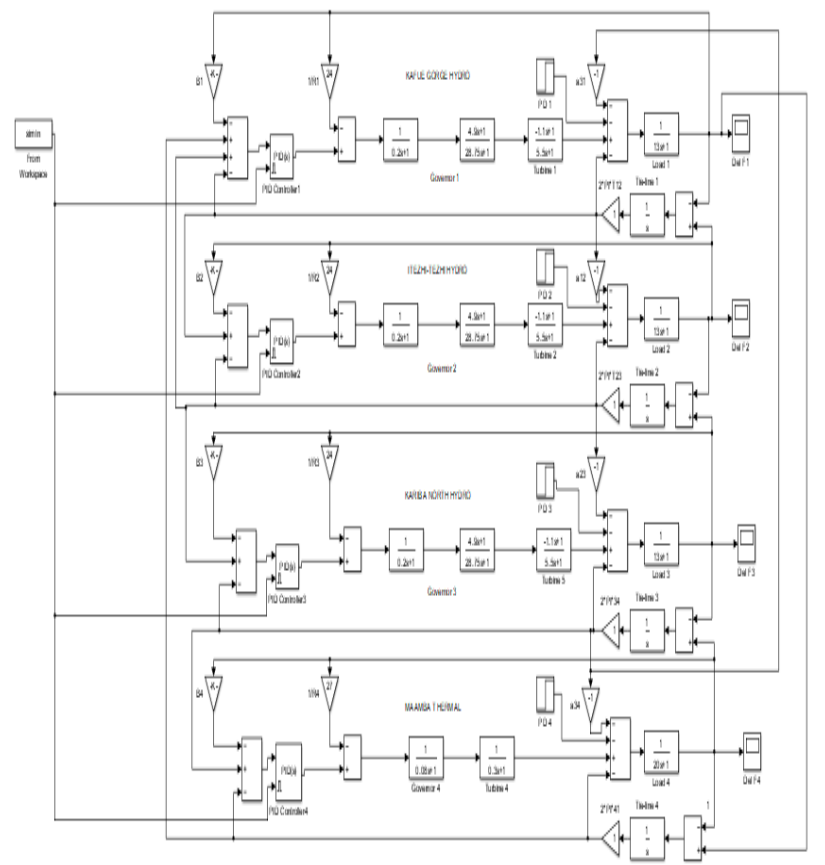

Fig. 3.2 Simulink model for LFC

A. Non-reheat Steam Turbine (Maamba Power Station)

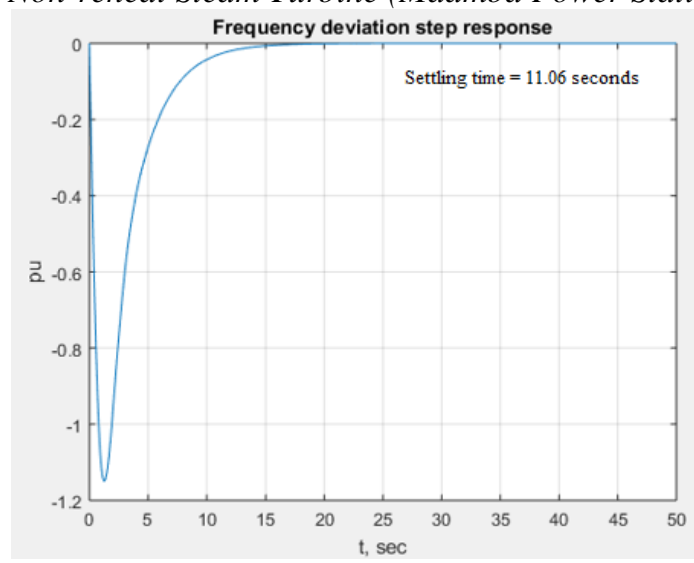

Fig 3.3 Frequency deviation response at Maamba Steam Turbine
B. Hydro Turbine (Kafue Gorge)

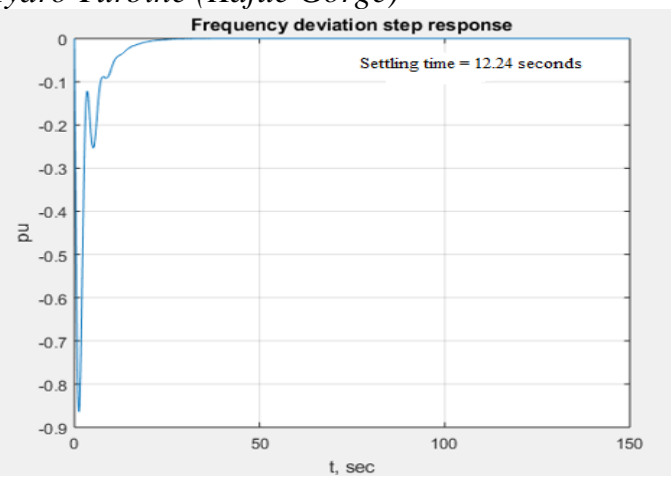

Fig 3.4 Frequency deviation response at Kafue Hydro Turbine

C. Kariba North Hydro Power Plant

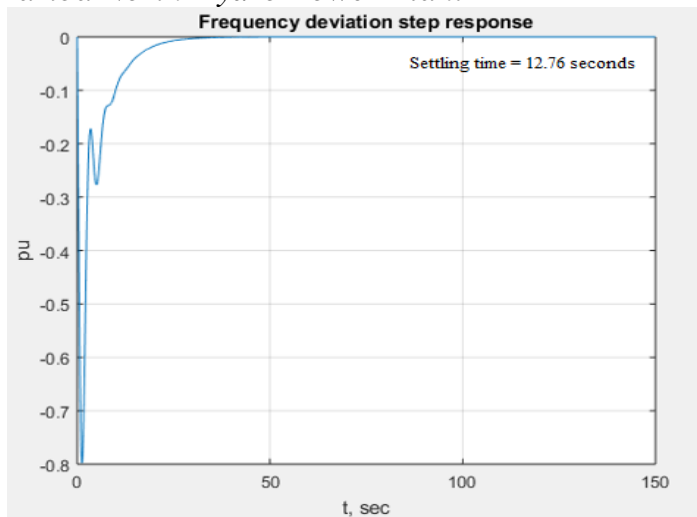

Fig 3.5 Frequency deviation response at Kariba Hydro Turbine

D. Itezhi-Tezhi North Hydro Power Plant

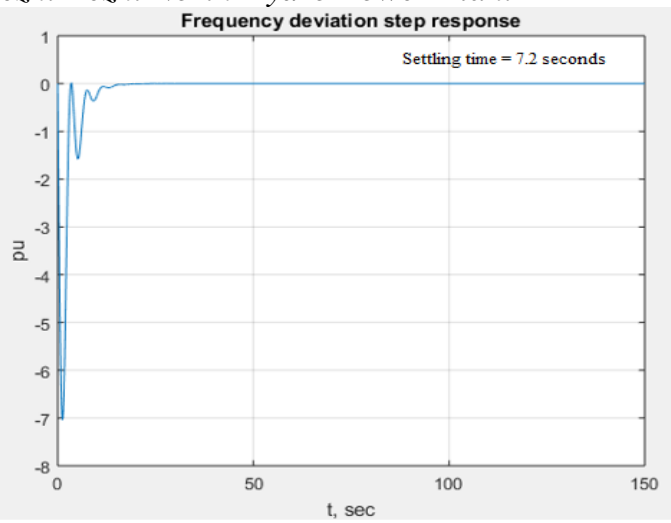

Fig 3.6 Frequency deviation response at Itezhi-tezhi Hydro Turbine

\section{DISCUSSION AND CONCLUSION}

To determine the effectiveness of PSO - PID Controller, simulation results are compared with isolated area AGC Frequency Deviation step responses of the power stations (areas) at Maamba, Kafue Gorge, Kariba North Bank and Itezhi-Tezhi. The desired settling times for frequency deviation step response to ensure system stability and economy of power generation is 15 seconds. Results from AGC frequency deviation step response is 76.67 seconds at Maamba, 55 seconds at Kafue Gorge, 57.06 seconds at Kariba and 56.04 seconds at Itezhi-Tezhi power stations. In effect, the generators units at the four locations will be practically bypassed by control relays will practically trip-out the generators and result in power blackout. 
In summary, there are three major factors that contribute to instability of the power system in Zambia;

i. Large power transients depicted in the frequency deviation step response;

ii. Large settling times with potential to violate pre-set control values of generators; and

iii. Need for large gain margins that are above generator system design.

After running the M-file of Particle Swarm Optimization (PSO) to improve performance and applying $K_{p}, K_{i}$ and $K_{d}$ values to the Simulink model yields the following results. Frequency deviation step response at Maamba is 11.06 seconds, 12.24 seconds at Kafue Gorge, 12.76 seconds at Kariba and 7.2 seconds at Itezhi-Tezhi power stations.

Less ripple appears in the output depicted from the frequency deviation step response when PSO algorithm regulates PID controller gains. There is system compensation when the power system incorporates generation control centers for LFC optimization. The system reaches equilibrium faster than in isolated area AGC system.

Results from PSO-PID controller demonstrate that the frequency deviation step response of the power system can be optimized to accommodate the most critical load change of the Electricity Supply Industry in Zambia, equal to the largest single mining load connected to the grid. Power system stability and economy of power generation realized.

\section{REFERENCES}

[1]. Energy Regulation Board (ERB), "Energy Sector Report" 2017

[2]. Southern Africa Global Competitiveness, "Electricity Supply industry of Zambia" March, 2008

[3]. Maamba Collieries Power Generation Project, P-ZM-F00-001, 2016

[4]. Mulungushi Hydropower Project - Environmental and Social Impact Assessment (ESIA)" Draft Scoping Report"2013

[5]. Zambia Bureau of Standards" Power Quality and Reliability Standard" DZS 387-1: 2009

[6]. Mikael Amelin, Power system planning "Frequency Control"2017

[7]. S. Sumathi L. Ashok Kumar Surekha P. "Computational Intelligence Paradigms for Optimization Problems Using MATLAB $® / S I M U L I N K "$ International Standard Book Number-13: 978-1-4987-4371-6, 2016 by Taylor \& Francis Group, LLC

[8]. R.C..Eberhart and Y.Shi, "Comparison between genetic algorithms and particle swarm optimization," in Proc. IEEE Int. Conf. Evol. Comput., Anchorage, AK, May 1998, pp. 611-616.

[9]. Gummadi Srinivasa Rao, Y.P.Obulesh , Miss.M.Kavya, "Tuning of PID Controller in Multi Area Interconnected Power System Using Particle Swarm Optimization" IOSR Journal of Electrical and Electronics Engineering (IOSR-JEEE), ISSN: 2320-3331, Volume 10, Issue 3 Ver. IV (May - Jun. 2015), 